\title{
PROSES PENURUNAN ZAT WARNA DALAM LIMBAH CAIR INDUSTRI SARUNG SAMARINDA DENGAN METODE ELEKTROKOAGULASI
}

\section{THE DECREASING PROCESS OF COLOUR COMPOUND IN LIQUID WASTE OF INDUSTRY SARUNG SAMARINDA WITH ELECTROCOAGULATION METHODE}

\author{
Dedy Irawan, Zainal Arifin, Emma Maulidya \\ Jurusan Teknik Kimia - Politeknik Negeri Samarinda \\ Email : ddy_iwn@yahoo.com
}

Naskah diterima 3 November 2011, disetujui 20 Maret 2012

\begin{abstract}
ABSTRAK
Industri Sarung Samarinda disamping menghasilkan produk sarung khas kota Samarinda juga menghasilkan limbah cair yang berasal dari proses pewarnaan benangnya. Limbah cair tersebut berpotensi mencemari lingkungan karena kandungan zat warna, sehingga perlu diolah sebelum dibuang. Tujuan dari penelitian ini adalah untuk menurunkan zat warna direct black 38 dalam limbah cair industri sarung tenun setelah melalui proses elektrokoagulasi. Penelitian dilakukan dengan menvariasikan tegangan listrik 6 - 12 volt, jarak elektroda $3-7 \mathrm{~cm}$ dan lama proses 45 - 225 menit dilakukan pada suatu unit pengolahan limbah cair sistem batch dengan kapasitas satu liter untuk mendapatkan kondisi terbaik agar zat warna yang terdapat dalam limbah cair terpisah sabanyak mungkin. Pengukuran zat warna menggunakan alat spektrofotometri pada panjang gelombang $505 \mathrm{~nm}$. Kondisi terbaik tercapai pada tegangan listrik 9 Volt, waktu 180 menit dan jarak elektroda $3 \mathrm{~cm}$ dengan $\%$ penghilangan zat warna hingga $94,29 \%$. Penerapan metode ini diharapkan menjadi salah satu alternatif pengolahan limbah cair industri Sarung Samarinda yang lebih efisien dan dapat mencegah pencemaran air sungai yang disebabkan zat warna.
\end{abstract}

Kata Kunci : elektrokoagulasi, jarak elektroda, limbah cair, sarung Samarinda, tegangan, waktu

\begin{abstract}
Industry of sarung samarinda products original handicraft from Samarinda province. Except it, liquid wastes also given production from color processing. The wastes have a bad potency because of colour contain. In order to, it was needing process before as a garbage to environment. The main research has decrease colour compound of direct black 38 in liquid waste from fabrication. It was done after electrocoagulation process. The variable studied were voltage between 6-12 volt, space of electrode between 3-7 cm, time of process between 3-7 cm, time of process between 45-225 minutes in the batch reactor with capacity one litres. it made for get the best condition. The experiment result show wave length of $505 \mathrm{~nm}$ with spectrofotometry device. Based on product, the best of voltage electricity of 9 volt, time of process 180 minutes, and space of electrode $3 \mathrm{~cm}$. In order to, the best result can decrease color concentration of $94,29 \%$. That method could be one of alternative decrease of waste Sarung Samarinda Industry.
\end{abstract}

Keywords: electrocoagulation, sarung samarinda, space of electrode, time, wastewater, voltage 


\section{PENDAHULUAN}

I \begin{tabular}{lrrr} 
ndustri & sarung & \multicolumn{2}{c}{ Samarinda } \\
merupakan & salah & satu industri \\
tradisional & khas & dari & kota
\end{tabular} Samarinda, merupakan industri rumah tangga yang sering kali terabaikan penanganan limbah cair yang dihasilkan dari proses pewarnaan benang yang akan ditenun menjadi sarung. Salah satu sentra industri sarung Samarinda berada di Kelurahan Mesjid Kecamatan Samarinda Seberang, yang letaknya di pinggiran sungai Mahakam, mencapai 60 industri (Guntur, 2010).

Limbah cair industri sarung tenun mengandung zat pewarna bila dibuang ke perairan akan menutupi badan air sehingga menghalangi sinar matahari yang masuk ke dalam perairan. Selain itu, badan air yang tercemar oleh limbah tekstil juga sangat berbahaya bila digunakan oleh manusia untuk kebutuhan sehari-hari. Hal ini dikarenakan beberapa senyawa kimia dari limbah tekstil mempunyai sifat racun bagi mahluk hidup yang dapat menyebabkan berbagai penyakit seperti kanker dan tidak berfungsinya organorgan tubuh bahkan dapat menyebabkan kematian (Hardi, 2003). Untuk menangani hal tersebut, maka perlu dilakukan suatu upaya pengolahan terhadap limbah cair tersebut.

Intensitas warna pada limbah cair dapat dikurangi dengan cara fisika, kimia maupun biologi. Metode dekolorisasi limbah cair industri tekstil antara lain: adsorpsi (Phalakornkule dkk, 2010), koagulasi/flokulasi (Zonoozi dkk, 2008), membran (Ahmad, 2002), nanofiltrasi (Hassani dkk, 2008), elektrokoagulasi (Alinsafi dkk, 2005), ozonasi (Konsowa, 2003), ultrasonik (Lorimer, 2001), dan biosorpsi (Low, 1995). Beberapa metode tersebut di atas telah terbukti efektif, meskipun terdapat beberapa kelemahan dan keterbatasan seperti tingginya kebutuhan energi, tidak efisien dan terbentuk limbah baru yang perlu diproses lagi.
Elektrokoagulasi merupakan suatu proses koagulasi kontinyu dengan menggunakan arus listrik searah melalui peristiwa elektrokimia, yaitu gejala dekomposisi elektrolit. Teknologi elektrokoagulasi untuk mendegradasi zat warna dimungkinkan untuk aplikasi di lapangan. Pada proses elektrokoagulasi akan terjadi pelepasan $\mathrm{Al}^{3+}$ dari plat elektroda (anoda) sehingga membentuk flok $\mathrm{Al}(\mathrm{OH})_{3}$ yang mampu mengikat kontaminan dan partikelpartikel dalam limbah.

Untuk mengolah limbah dengan metode ini diperlukan elektroda yang tercelup dalam air limbah dan terhubung dengan sumber listrik. Degradasi zat warna terjadi karena terbentuknya spesies aktif yang terbentuk dari proses elektrokoagulasi tersebut. Destabilisasi koloid dari zat warna terjadi karena pelepasan ion Logam $(L)^{n+}$ dari Anoda pada kutub positif dan terlepasnya ion $\mathrm{H}^{+}$pada kutub negatif. Pelepasan $(L)^{n+}$ dari anoda akan bereaksi dengan air membentuk $\mathrm{L}(\mathrm{OH})_{n}$. Arus listrik yang melewati logam mengakibatkan terjadinya oksidasi logam sehingga terbentuk ion positif dari logam tersebut. Selanjutnya air tereduksi menjadi gas hidrogen dan $\mathrm{OH}^{-}$(Daneshvar et al., 2006)

Penelitian Purwaningsih (2008), mengolah limbah cair industri batik dengan metode elektrokoagulasi didapat $\%$ penurunan warna maksimum adalah $64,46 \%$. Penelitian-penelitian yang telah dilakukan sebelumnya masih menunjukkan bahwa proses pengolahan limbah cair dengan metode elektrokoagulasi masih perlu ditingkatkan kemampuannya dalam menurunkan kadar warna tersebut. Penelitian ini bertujuan untuk menurunkan kadar warna direct black 38 dalam limbah cair industri sarung tenun setelah melalui proses elektrokoagulasi dengan memvariasikan waktu, jarak elektroda dan tegangan listrik. 
BAHAN DAN METODA

\section{Bahan dan Alat}

Limbah cair industri sarung tenun Samarinda yang digunakan sebagai sampel dalam penelitian ini mengandung zat pewarna direct black 38 yang bersumber dari sentra pengrajin sarung tenun khas Samarinda di Kelurahan Masjid, Kecamatan Samarinda Seberang kota Samarinda.
Alat Penelitian yang digunakan antara lain bak elektrokoagulasi sebagai tempat proses pengolahan limbah cair, plat aluminium (ukuran $5,5 \mathrm{~cm} \times 4,6 \mathrm{~cm}$ ) yang dijadikan elektroda pada proses elektrokoagulasi, adaptor untuk pengatur tegangan dan alat spektrofotometri tipe UV-Vis Varian Cary 50 untuk analisa kadar warna.

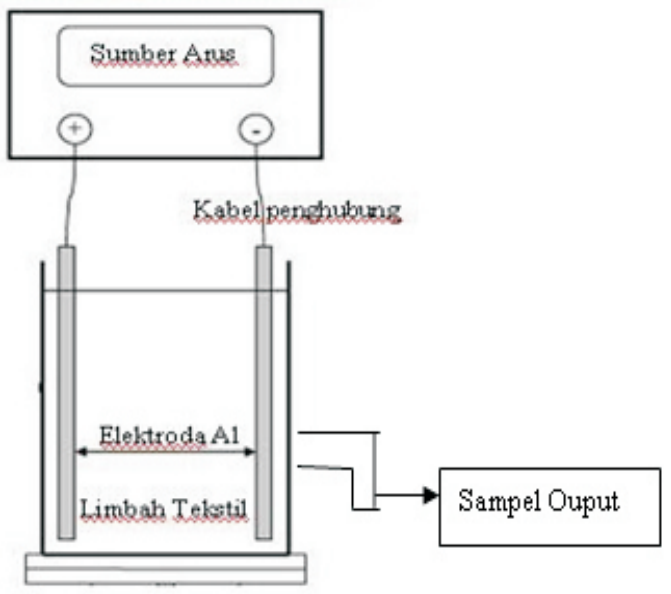

Gambar 1. Rangkaian Alat Pengolahan limbah cair dengan metode Elektrokoagulasi

\section{Metode Penelitian}

Penelitian diawali dengan membuat kurva standar dari larutan yang mengandung zat warna direct black 38 pada berbagai konsentrasi menggunakan alat UV-Vis Cary 50. Selanjutnya mengukur konsentrasi zat warna mula - mula yang terdapat dalam limbah cair dengan alat yang sama. Proses elektrokoagulasi dimulai dengan merangkai alat seperti pada gambar 1 , memastikan jarak antar plat elektroda sudah sesuai dengan yang divariasikan.

Limbah cair industri sarung tenun Samarinda yang mengandung pewarna direct black 38 sebanyak $1000 \mathrm{ml}$ dimasukkan dalam bak elektrokoagulsi. Proses elektrokoagulasi mulai dijalankan dengan menggunakan elektroda Aluminium (AI) yang terhubung dengan sumber listrik pada tegangan listrik diatur sesuai dengan yang divariasikan. Selanjutnya proses eletrokoagulasi berlangsung selama waktu yang divariasikan disertai dengan pengadukan lambat $130 \mathrm{rpm}$. Setelah proses dihentikan diamkan terlebih dahulu selama 15 menit, kemudian sampel di drain dan di tampung ke dalam botol sampel untuk diendapkan. Mengulangi tahapan proses tersebut dengan memvariasikan jarak elektroda $(3 \mathrm{~cm}, 5 \mathrm{~cm}$ dan $7 \mathrm{~cm})$ dan tegangan $(6$ Volt, 9 Volt dan 12 Volt) dan waktu (45 menit, 90 menit, 135 menit, 180 menit, 225 menit). Proses elektrokoagulasi sangat dipengaruhi oleh litrik yang digunakan, waktu proses dan jarak antar elektroda (Miron, dkk. 2010).

Analisa kandungan zat warna dengan mengkur absorbansi sampel menggunakan alat UV-Vis Cary 50. Kurva standar dibuat dengan menggunakan pewarna yang sama dengan pewarna yang terdapat dalam limbah cair yaitu direct black 38 pada berbagai konsentrasi dengan menggunakan panjang gelombang 505 
lagi mendestabilisasi partikel-partikel koloid (Miron, dkk. 2010).

\section{Pengaruh Tegangan Terhadap Proses Elektrokoagulasi \\ Pengaruh tegangan listrik} terhadap $\%$ penghilangan zat pewarna direct black 38 dapat dilihat pada gambar 3. Pada tegangan listrik 6 volt hingga 9 Volt terjadi peningkatan \% penghilangan zat warna dan selanjutnya turun pada tegangan listrik 12 Volt.

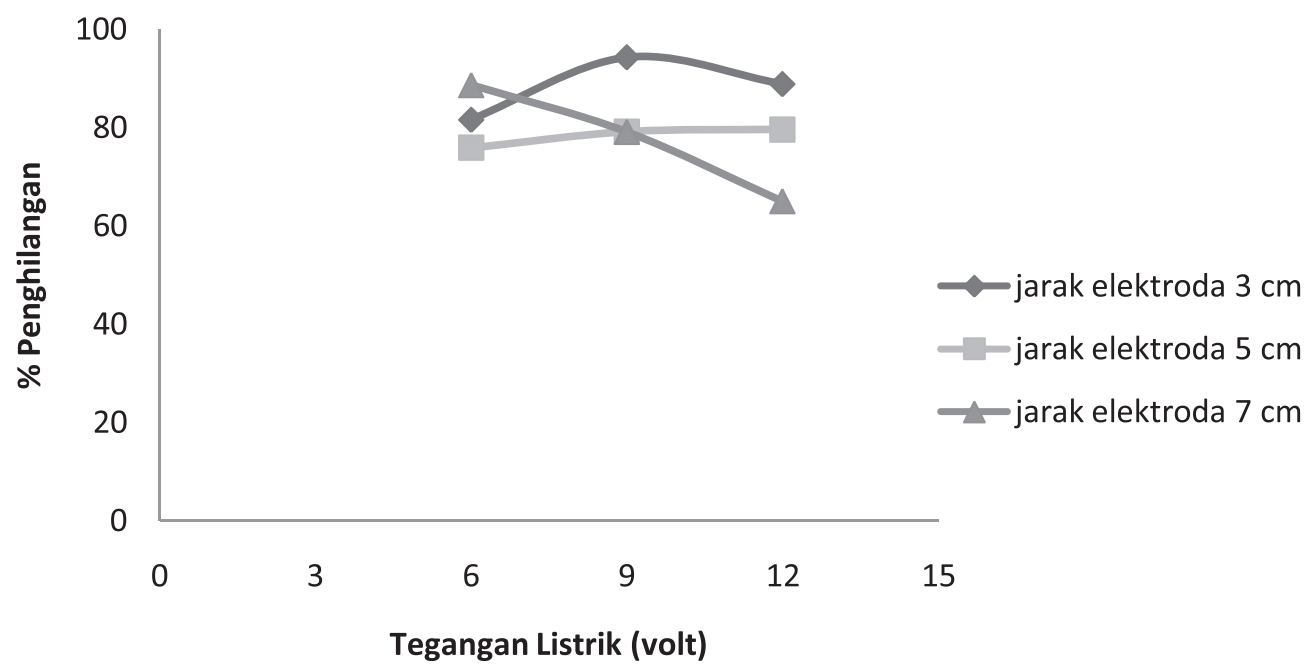

Gambar 3. Grafik hubungan antara \% penghilangan zat warna dengan tegangan listrik pada waktu 180 menit (Jarak eletroda 3, 5 dan $7 \mathrm{~cm}$ )

Hukum George Simon Ohm, menjelaskan bahwa kuat arus listrik dalam suatu penghantar berbanding lurus dengan tegangan listrik antara ujung-ujung penghantar asalkan suhu penghantar tetap. Pada tegangan listrik 12 Volt terjadi penurunan \% pengurangan warna direct black 38 , hal ini dikarenakan pada tegangan listrik 12 Volt cairan sudah cukup tinggi kandungan elektrolit yang mengakibatkan terjadi hubungan singkat antar elektroda (Alaton, dkk. 2008).

Dari grafik di atas, menunjukan bahwa pada jarak elektroda $7 \mathrm{~cm}$ terjadi penyimpangan yang tidak sesuai dengan hukum George Simon Ohm. Pada jarak $7 \mathrm{~cm}$ memberikan \% penghilangan yang tinggi sebesar $88,68 \%$ dan diikuti dengan jarak $3 \mathrm{~cm}$ sebesar $81,56 \%$ pada tegangan listrik 6 Volt. Selanjutnya pada jarak $7 \mathrm{~cm}$ semakin menurun pada tegangan 9 Volt dan 12 Volt. Hal ini dimungkinkan pada tegangan 6 volt pada jarak $7 \mathrm{~cm}$ tersebut bersifat elektrolit yang tidak terlalu tinggi sehingga dengan jarak 7 $\mathrm{cm}$ flok yang dihasilkan lebih stabil. Sedangkan pada tegangan 9 Volt dan 12 Volt \% pengurangan semakin menurun, hal ini disebabkan pada tegangan 9 Volt dan 12 Volt terjadi hubungan singkat antar elektroda sehingga pada jarak $7 \mathrm{~cm}$ tersebut mengakibatkan ketidakstabilan flok yang terbentuk.

\section{Pengaruh Jarak Elektroda Terhadap Proses Elektrokoagulasi}

Pada gambar 4, menunjukan bahwa penurunan kadar warna maksimum terjadi pada jarak elektroda 3 $\mathrm{cm}$, dibandingkan dengan jarak $5 \mathrm{~cm}$ dan $7 \mathrm{~cm}$ pada waktu 180 menit. Jarak elektroda $3 \mathrm{~cm}$ didapatkan \% penurunan sebesar $94,29 \%$, jarak elektroda $5 \mathrm{~cm} \%$ penurunan sebesar $79,12 \%$ dan pada jarak elektroda $7 \mathrm{~cm} \%$ pengurangan sebesar $79,12 \%$. 


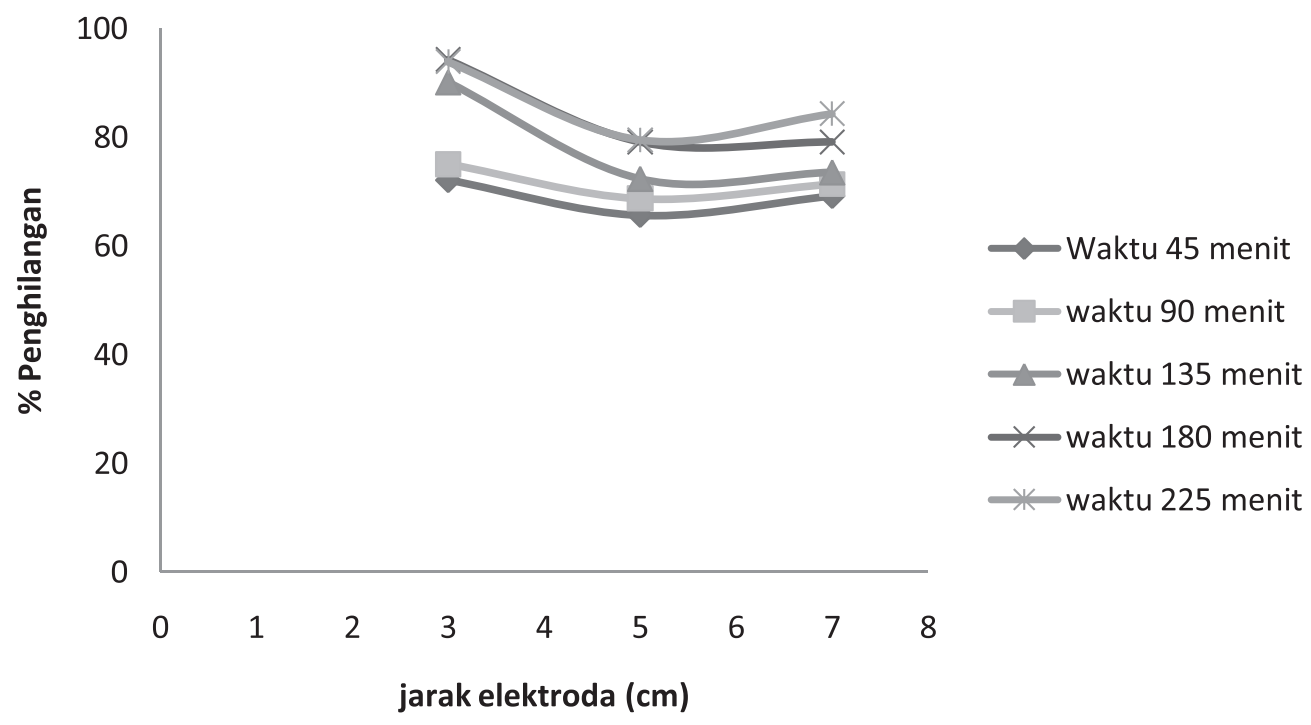

Gambar 4.Grafik \% penghilangan dengan jarak elektroda pada tegangan listrik 9 Volt (dengan waktu 45, 90, 135, 180 dan 225 menit)

Dalam penelitian ini jarak elektroda yang paling dekat yang memiliki \% penghilangan zat warna yang tinggi. Hal ini dikarenakan semakin dekat jarak elektroda, maka semakin besar koagulan yang terbentuk oleh besarnya arus listrik yang diberikan, sehingga endapan dan flok yang dihasilkan lebih banyak (Miron, dkk. 2010). Jarak elektroda $5 \mathrm{~cm}$ terjadi penurunan $\%$ pengurangan, dikarenakan semakin jauh jarak elektroda maka flok yang terbentuk oleh arus listrik yang dihasilkan jauh lebih sedikit. Jarak elektroda $7 \mathrm{~cm}$ didapatkan sama dengan pada jarak elektoda $5 \mathrm{~cm}$, hal ini menunjukan pada jarak elektroda $5 \mathrm{~cm}$ dan $7 \mathrm{~cm}$ bahwa koagulan yang dihasilkan dari reaksi oksidasi reduksi pada proses elektrokoagulasi ini telah mengalami titik jenuh atau tidak mampu lagi mendestabilisasi partikel-partikel koloid.

\section{KESIMPULAN}

Proses pengolahan limbah cair industri sarung Samarinda dengan metode elektrokoagulasi yang telah dilakukan pada penelitian ini didapat beberapa informasi yang dapat dijadikan acuan proses. Tegangan listrik,waktu, dan jarak elektroda yang digunakan dalam proses elektrokoagulasi dapat meningkatkan \% pengurangan. Kondisi proses elektrokoagulasi untuk menurunkan zat waran direct black 38 memberikan \% peghilangan zat warna tertinggi pada tegangan listrik 9 Volt, waktu 180 menit dan jarak elektroda 3 cm sebesar $94,29 \%$.

\section{DAFTAR PUSTAKA}

Ahmad. A. 2002. Removal of Dye From Wastewater of Textile Industry Using Membrane Technology. Malaysian: University Technology of Malaysian.

Alaton, A., Kabda, I., Sahin, Y., 2008. Effect of Operating Parameters on the Electrocoagulation of Simulated Acid Dyebath Effluent. The Open Environmental \& Biological Monitoring Journal. Vol. 1. Pp. 1-7

Alinsafi, A., Khemis, M., Pons, M.N. Leclerc, Yaacoubi., 2005. Electro-coagulation of reactive textile dyes and textile wastewater. Chemical Engineering and Processing . Elsevier. Vol. 44. pp. 461-470 
Daneshvar, N., Khataee, A.R., Amani Ghadim, A.R., Rasoulifard, M.H., 2007. Decolorization of C.I. acid yellow 23 solution by electrocoagulation process: investigation of operational parameters and evaluation of specific electrical energy consumption (SEEC). J. Hazard. Mater 148 (3), 566-572

Guntur, M. 2010. Daftar Nama Pengerajin Industri Sarun. Samarinda: Kelurahan Mesjid. Kecamatan Samarinda Seberang. Samarinda.

Hardi, M. 2003. Pengglahan Air Limbah Industri Tesktil dengan Metode Fotdkimia uv-h202.Jakarta : Universitas Indonesia.

Hasani, 2008. Nanofiltration Process On Dye Removal Simulated TextileWastewater. Tehran.Iran : Islamic Azad University.

Johanes. H. 1978.Listrik Dan Magnet. Balai Pustaka. Jakarta.

Konsowa, A.H. 2003. Decolorization of Wastewater Containing direct Dye by Ozonation in Batch Bubble Colomn Reactor.Alexandria: Alexandria University.

Lorimer, J.P. 2001. Degradation of Dye Effluent. Journal of Pure ApplChem. IUPAC. North Carolina, USA. Vol. 73.No. 12. pp. 1957-1968.
Low, K.S. 1995. Biosorption of Basic Dyes by Water Hyacinth Roots. Selangor Malaysia : University of Agriculture Malaysia.

Miron, A., Modrogan, C., Daniela, O., Orbulet. 2010. Evaluation of Electro Coagulation Process Performances for Decolorization of Alizarin Saphirol Containing Solution. Revitiade Chimie. Bucharest. Vol. 61. No. 7. pp. 646 - 650

Phalakornkule, C. Polgumhang, S. Tongdaung, W. 2010. Electrocoagulation of blue reactive, red disperse and mixed dyes and application in treating textile effluent, Journal of Environmental Management. Vol. 91. pp. 918-926

Purwaningsih, I. 2008.Pengolahan Limbah Cair Industri Batik CV. Batik Indah Raradjonggrang Yogyakarta dengan Metode Elektrokoagulasi ditinjau dari parameter COD dan Warna. Yogyakarta: Universitas Islam Indonesia.

Zonoozi, H. 2008. Removal of Acid Red 398 Dye From Aqueous Solution by Coagulation/Flocculation Process. The Tehran.Iran : Journal of Environmental and management Journal. Vol 7.no 6 . 695-699. 